\title{
The Association of Hair Coloring During Pregnancy With Pregnancy and Neonatal Outcomes: A Cross-sectional Study
}

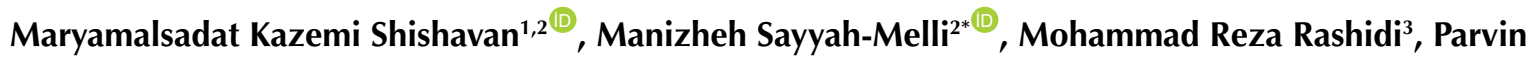 \\ Mostafa Gharabaghi ${ }^{2}$, Morteza Ghojazadeh ${ }^{4}$, Vahideh Rahmani ${ }^{2}$, Zohreh Tahmasebi ${ }^{5}$
}

\begin{abstract}
Objectives: Using hair dye has spread globally in recent years. Concerns have arisen about the safety of hair dyes during pregnancy. The primary goal of this study was to examine the association between hair coloring and pregnancy outcomes.

Materials and Methods: This cross-sectional study was conducted on 2040 pregnant women aged 14 to 48 years, in Talegani teaching hospital of Tabriz University of Medical Sciences from January 2017 to December 2019. Three trained midwives collected relevant information from the women on the admission to the labor room and recorded pregnancy outcomes. Chi-square test of independence with post hoc tests and logistic regression analysis were used for data analysis. Odds ratios with a 95\% confidence interval and contributing effect sizes were reported. The significance level was set at $P \leq 0.05$.

Results: The majority of participants $(62.67 \%)$ colored their hair in the third trimester. There was no statistically significant association between hair coloring and neonate 1-minute $(P=0.23)$ and 5 -minute Apgar scores $(P=0.99)$. The logistic regression model did not confirm a rise in overall neonatal complications (NCs) associated with hair coloring at any time during the pregnancy (odds ratio [OR]: 0.027, $P<0.001)$. Higher rates of low birth weight $(L B W)$ were seen among those who dyed their hair in the preconception period and third trimester compared to the woman who colored their hair in the first and second trimesters $(P<0.001)$.

Conclusions: We observed associations between hair coloring and LBW, however there were no increased odds for NC. The evidence for the safety of hair dye during pregnancy is still limited.

Keywords: Apgar score, Hair dye, Infant low birth weight, Infant newborn diseases, Pregnancy, Preterm labor
\end{abstract}

\section{Introduction}

Pregnancy is a determining period for both mother and fetus. No mother would jeopardize her baby's health at any cost. Nowadays, most women dye their hair at some points in their lives, sometimes as early as 18 years old (13). It is not clear whether hair color would affect the fetus or not. Studies have shown a possible association between hair coloring during pregnancy, and low birth weight (LBW), neuroblastoma, and leukemia in the offspring (47). There is a report on increased neonatal abnormalities in mothers who used chlorinated solvents and glycol ether for hair dyeing during pregnancy. Still, the report was criticized because of the lack of biological plausibility (8). Blackmore-Prince et al failed to show the association of dyeing hair three months before pregnancy and during pregnancy with preterm labor or LBW in black women (9). Different studies raised concerns about the association of the effect of glycol ethers and oxygenated solvents which are used in cosmetic products with neurocognitive abnormalities and potential developmental effects on the male genital system $(10,11)$, and thus far, studies have failed to prove the adverse association (12).

Despite limited evidence on the adverse effects of hair coloring during pregnancy, with a justification of "minimal systemic absorption on healthy skin", hair dyes are considered to be safe during pregnancy (13, 14). However, there is no convincing evidence aimed to examine the relationships between hair coloring during pregnancy and other unwanted outcomes. According to our clinical experience, most Iranian women believe that hair coloring during pregnancy would affect the child; however, if they want to dye their hair, they do it at the end of the third trimester. Considering these, the main goal of this study was to examine the association between hair coloring and intrapartum and neonatal outcomes such as preterm labor and Apgar scores.

\section{Materials and Methods}

This was an explorative cross-sectional study; therefore, we did not use a formal sample size calculation and evaluated all participants' data. The study was carried out in Talegani teaching hospital of Tabriz University of 
Key Messages

- Hair coloring during pregnancy is weakly associated with neonate's low birth weight; However, the strength and extent of the evidence are not sufficient to conclude that the use of hair colors during pregnancy is harmful, nor is it enough to recommend its safety.

Medical Sciences from January 2017 to December 2019. All pregnant women who were admitted to the labor room were eligible for participation in the study. To minimize the confounding factors, we excluded the mothers with a medical history of diabetes, thyroid disorders, cardiovascular and renal diseases, autoimmune diseases, hematological abnormalities, psychotic disorders, confirmed infectious diseases, and a history of drug abuse. Hairdressers and beauty salon workers were also excluded. Three trained midwives described the study to the mothers during admission. After consenting to participate, mothers were asked about their hair coloring history before conception and during pregnancy. Demographic information, pregnancy complications, and neonatal outcomes were extracted from the patients' and neonates' hospital files and recorded in the data collection forms. The information included prepartum complications such as premature rupture of membranes (PROM), preterm labor, abruptio placentae (also called placental abruption), and so on. The date of delivery, delivery method (vaginal, cesarean section), delivery operator (Ob/Gyn specialist/ midwife), and gestational age at delivery were also documented. Recorded neonatal outcomes were neonatal birth weight in grams, neonatal Apgar scores, congenital malformations, and neonatal complications (NCs) including asphyxia, respiratory distress syndrome, meconium aspiration syndrome, sepsis, neonatal hemorrhage, hydrops, kernicterus, and hypoglycemia. Data gathered for hair coloring history consisted of the following: whether they dyed their hair or not, the time of coloring, the product origin (domestic or foreign product), the number of standard color tubes as an indicator of the amount of color used, the frequency and style of hair coloring, and the color of dye (a spectrum of dark or fair colors). We defined the time of coloring as preconception (3 months before conception) and pregnancy trimesters. We reported the dye material used as tube units (half of a tube $* 2$ rounds of use $=1$ tube). We categorized Apgar scores in two groups. Scores of 8-10 were considered favorable, and scores 7 and less were considered unfavorable.

\section{Statistical Analysis}

Continuous variables were presented as means \pm standard deviations (SD). Categorical variables were presented as frequency and percentages. Chi-square test of independence with post hoc tests was used for testing associations between categorical variables. We used the logistic regression analysis to predict the relationship between NCs and variables of hair coloring history. Contributing effect sizes of associations and odds ratio with a 95\% confidence interval were reported. The significance level was set at $\alpha \leq 0.05$, representing $95 \%$ confidence interval. We reported post hoc $P$ values after Bonferroni correction.

\section{Results}

We studied 2040 women aged 14 to 48 , with a mean age of 26.56 years old. Most women $(93.69 \%)$ were on their first (19.46\%), second (18.58\%), or third (7.84\%) pregnancies. Among all participants, 464 (22.75\%) were from rural areas, while the rest $(77.25 \%)$ were from urban ones. The proportion of congenital malformation was low $(0.78 \%)$, and the records showed that only $42(2.06 \%)$ of neonates experienced NCs. Detailed information about the maternal demographic information, prepartum events, NCs, and type of delivery is available in Supplementary file 1.

Among total number of mothers who dyed their hair during pregnancy (75.24\%), the majority (62.67\%) colored their hair in the third trimester. There was no statistically significant association between hair coloring and neonate 1-minute $(P=0.23)$ and 5-minute Apgar scores $(P=0.99)$. In subgroup analysis, chi-square test of independence with post hoc tests showed that the neonates of the women who dyed their hair in the preconception period had more unfavorable 1-minute Apgar scores $(P<0.0001)$.

The comparative results of chi-square test of independence for overall NCs and birth weight categories according to hair coloring indices are displayed in Tables 1 and 2.

NCs were more prevalent among the women who had never dyed their hair before conception, than that among others $(P<0.001)$. Therefore, we ran a subgroup analysis using post hoc chi-square test to examine the differences in NCs among the participants who dyed their hair preconception or during pregnancy. Test results revealed that the recorded NCs were higher among women who had dyed their hair in the preconception period in comparison to those who dyed their hair during pregnancy trimester $(P<0.001)$. Similarly, the post hoc Chi-square test showed that using approximately two tubes of coloring material was significantly associated with higher rates of neonatal adverse outcomes $(P=0.002)$.

When comparing NCs in the categories of "product origin" and "style of hair coloring", NCs were recorded more frequently among mothers who did not color their hair $(P<0.001)$. However, the prevalence of NCs was statistically similar in different categories of product origin and the style of hair coloring (Bonferroni correction, $P>0.006)$.

We performed logistic regression analysis to ascertain the effects of the period of using hair color, the product 
Table 1. Comparisons of the Frequency of Neonatal Complications According to Coloring Characteristics

\begin{tabular}{|c|c|c|c|c|}
\hline Characteristics & Overall Sample & Complication & No Complication & Chi-Square Test of Independence \\
\hline \multicolumn{5}{|l|}{ Period of coloring } \\
\hline No coloring & $505(24.75 \%)$ & $22(52.38 \%)$ & $483(24.17 \%)$ & \multirow{5}{*}{$\begin{array}{c}\chi^{2}(4)=85.10 \\
P<0.001 \\
{ }^{\mathrm{a}} \varphi=0.014 \\
\mathrm{n}=2040\end{array}$} \\
\hline Pre-pregnancy & $159(7.79 \%)$ & $16(38.10 \%)$ & $143(7.16 \%)$ & \\
\hline First trimester & $343(16.81 \%)$ & $1(2.38 \%)$ & $342(17.12 \%)$ & \\
\hline Second trimester & $71(3.48 \%)$ & $0(0.00 \%)$ & $71(3.55 \%)$ & \\
\hline Third trimester & $962(47.16 \%)$ & $3(7.14 \%)$ & $959(48.00 \%)$ & \\
\hline \multicolumn{5}{|l|}{ Product origin } \\
\hline No coloring & $505(24.75 \%)$ & $22(52.38 \%)$ & $483(24.17 \%)$ & \multirow{4}{*}{$\begin{array}{c}\chi^{2}(3)=18.73 \\
P<0.001 \\
{ }^{\mathrm{b}} \varphi=0.09 \\
\mathrm{n}=2040\end{array}$} \\
\hline Domestic product & $1023(50.15 \%)$ & $14(33.33 \%)$ & $1009(50.50 \%)$ & \\
\hline Foreign product & $311(15.25 \%)$ & $2(4.76 \%)$ & $309(15.47 \%)$ & \\
\hline Unknown & $201(9.85 \%)$ & $4(9.52 \%)$ & $197(9.86 \%)$ & \\
\hline \multicolumn{5}{|c|}{ Number of standard color tubes used } \\
\hline No coloring & $505(24.75 \%)$ & $22(52.38 \%)$ & $483(24.17 \%)$ & \multirow{5}{*}{$\begin{array}{c}\chi^{2}(4)=33.67 \\
P<0.001 \\
{ }^{\mathrm{b}} \varphi=0.12 \\
\mathrm{n}=2040\end{array}$} \\
\hline 0.5 tube & $362(17.75 \%)$ & $6(14.29 \%)$ & $356(17.82 \%)$ & \\
\hline One tube & $973(47.70 \%)$ & $5(11.90 \%)$ & $986(48.45 \%)$ & \\
\hline Two tubes & $176(8.63 \%)$ & $9(21.43 \%)$ & $167(8.36 \%)$ & \\
\hline Four tubes & $24(1.18 \%)$ & $0.0(\%)$ & $24(1.20 \%)$ & \\
\hline \multicolumn{5}{|l|}{ Style of coloring } \\
\hline No coloring & $505(24.75 \%)$ & $22(52.38 \%)$ & $483(24.17 \%)$ & \multirow{4}{*}{$\begin{array}{c}\chi^{2}(4)=27.96 \\
P<0.001 \\
{ }^{\mathrm{b}} \varphi=0.11 \\
\mathrm{n}=2040\end{array}$} \\
\hline Bleaching & $36(1.76 \%)$ & $3(7.14 \%)$ & $33(1.65 \%)$ & \\
\hline Simple coloring & $1180(57.84 \%)$ & $16(38.10 \%)$ & $1164(58.26 \%)$ & \\
\hline Salt and pepper & $319(15.64 \%)$ & $1(2.38 \%)$ & $318(15.92 \%)$ & \\
\hline \multicolumn{5}{|l|}{ Color of dye } \\
\hline Bright & $428(27.88 \%)$ & $1(5.00 \%)$ & $427(28.18 \%)$ & \multirow{3}{*}{$\begin{array}{c}\chi^{2}(1)=5.27 \\
P=0.02 \\
{ }^{\mathrm{b}} \varphi=0.05 \\
\mathrm{n}=1535\end{array}$} \\
\hline Dark & $1107(72.12 \%)$ & $19(95.00 \%)$ & $1088(71.82 \%)$ & \\
\hline Dark or bright & $0(0 \%)$ & $0(0 \%)$ & $0(0 \%)$ & \\
\hline
\end{tabular}

$\varphi=$ effect size (phi coefficient or Cramer's V).

a A significant difference with an effect size $\geq$ Cohen's definition of "medium".

${ }^{\text {b }}$ A significant difference with an effect size $\geq$ Cohen's definition of "small."

origin, the amount of the hair dye used, and the style of hair coloring on the likelihood that neonates experience adverse outcomes. The logistic regression model was statistically significant $\left(\chi^{2}(11)=82.71, P<0.001\right)$. The model explained $21.9 \%$ (Nagelkerke $R 2$ ) of the variance in neonatal adverse outcomes and correctly classified $98.1 \%$ of cases. Neonates born to women who dyed their hair in the preconception period were less likely to exhibit NCs than babies of the women who did not use hair dye and the women who dyed their hair during pregnancy trimester (OR: 0.027, CI 95\%: 0.007-0.108, $P<0.001$ ). The likelihood of adverse neonate outcomes was not associated with other hair coloring variables $(P>0.1)$.

A Chi-square test of independence revealed that birth weight categories were significantly associated with the hair coloring period $(P<0.001)$. Post hoc comparisons of rates of LBW with the period of hair coloring revealed that higher rates of LBW were seen among those who dyed their hair in the preconception period and third trimester $(P<0.001)$. The LBW prevalence was statistically similar among those who colored their hair in the first and second trimesters and those who did not color their hair
(Bonferroni correction, $P<0.002)$. Very low birth weight (VLBW) and high birth weight (HBW) prevalence was statistically similar among all groups $(P>0.002)$.

Although the chi-square test of independence showed significant associations between birth weight categories and product origin, the style of hair coloring, and the amount of color used, post hoc tests revealed that rates of VLBW, LBW, and HBW were statistically similar among all groups (Table 2).

Chi-square test of independence depicted a higher prevalence of the abruptio placentae $(P<0.001)$ and PROM $(P<0.001)$ in women who did not dye their hair. On the other hand, higher rates of preterm labor were recorded among the women who used hair coloring $\left(r^{2}(4)=43.94\right.$, $P<0.001, \varphi=0.014)$. Subgroup comparison with post hoc chi-square test revealed that women who dyed their hair on the third trimester experienced statistically significant higher rates of preterm labor $(P<0.0001)$.

\section{Discussion}

Using hair dye has increased globally and rapidly in recent years. Scientists have investigated the relationships 
Table 2. Comparisons of the Newborn's Weight Categories According to Coloring Characteristics

\begin{tabular}{|c|c|c|c|c|c|c|}
\hline Characteristics & Overall Sample & VLBW & LBW & NBW & HBW & $\begin{array}{c}\text { Chi-Square Test of } \\
\text { Independence }\end{array}$ \\
\hline \multicolumn{7}{|l|}{ Period of coloring } \\
\hline No coloring & $505(24.75 \%)$ & $1(11.11 \%)$ & $35(23.18 \%)$ & $447(24.53 \%)$ & $22(37.93 \%)$ & \multirow{5}{*}{$\begin{array}{c}\chi^{2}(12)=77.39 \\
P<0.001 \\
{ }^{\mathrm{a}} \varphi=0.19 \\
\mathrm{n}=2040\end{array}$} \\
\hline Pre-pregnancy & $159(7.79 \%)$ & $5(55.56 \%)$ & $24(15.89 \%)$ & $121(6.64 \%)$ & $9(15.52 \%)$ & \\
\hline First trimester & $343(16.81 \%)$ & $3(33.33 \%)$ & $38(25.17 \%)$ & $296(16.25 \%)$ & $6(10.34 \%)$ & \\
\hline Second trimester & $71(3.48 \%)$ & $0(0.00 \%)$ & $5(3.31 \%)$ & $66(3.62 \%)$ & $0(0.00 \%)$ & \\
\hline Third trimester & $962(47.16 \%)$ & $0(0.00 \%)$ & $49(32.45 \%)$ & $892(48.96 \%)$ & $21(36.21 \%)$ & \\
\hline \multicolumn{7}{|l|}{ Product origin } \\
\hline No coloring & $505(24.75 \%)$ & $1(11.11 \%)$ & $35(23.18 \%)$ & $447(24.53 \%)$ & $22(37.93 \%)$ & \multirow{4}{*}{$\begin{array}{c}\chi^{2}(9)=18.89 \\
P=0.026 \\
{ }^{\mathrm{a}} \varphi=0.09 \\
\mathrm{n}=2040\end{array}$} \\
\hline Domestic product & $1023(50.15 \%)$ & $5(55.56 \%)$ & $73(48.34 \%)$ & $926(50.82 \%)$ & $19(32.76 \%)$ & \\
\hline Foreign product & $311(15.25 \%)$ & $0(0.00 \%)$ & $29(19.21 \%)$ & $274(15.04 \%)$ & $8(13.79 \%)$ & \\
\hline Unknown & $201(9.85 \%)$ & $3(33.33 \%)$ & $14(9.27 \%)$ & $175(9.60 \%)$ & $9(15.52 \%)$ & \\
\hline \multicolumn{7}{|c|}{ Amount of standard color tube used } \\
\hline No coloring & $505(24.75 \%)$ & $1(11.11 \%)$ & $35(23.18 \%)$ & $447(24.53 \%)$ & $22(37.93 \%)$ & \multirow{5}{*}{$\begin{array}{c}\chi^{2}(12)=24.86 \\
P=0.016 \\
{ }^{\mathrm{a}} \varphi=0.11 \\
\mathrm{n}=2040\end{array}$} \\
\hline 0.5 tube & $362(17.75 \%)$ & $1(11.11 \%)$ & $21(13.91 \%)$ & $328(18.00 \%)$ & $12(20.69 \%)$ & \\
\hline One tube & $973(47.70 \%)$ & $7(77.78 \%)$ & $68(45.03 \%)$ & $880(48.30 \%)$ & $18(31.03 \%)$ & \\
\hline Two tubes & $176(8.63 \%)$ & $0(0.00 \%)$ & $24(15.89 \%)$ & $146(8.01 \%)$ & $6(8.63 \%)$ & \\
\hline Four tubes & $24(1.18 \%)$ & $0(0.00 \%)$ & $3(1.99 \%)$ & $21(1.15 \%)$ & $0(0.00 \%)$ & \\
\hline \multicolumn{7}{|l|}{ Color of dye } \\
\hline Bright & $428(27.88 \%)$ & $4(50.00 \%)$ & $24(20.69 \%)$ & $393(28.58 \%)$ & $7(19.44 \%)$ & \multirow{3}{*}{$\begin{array}{c}\chi^{2}(3)=6.54 \\
P=0.088 \\
{ }^{\mathrm{b}} \varphi=0.06 \\
\mathrm{n}=2040\end{array}$} \\
\hline Dark & $1107(72.12 \%)$ & $4(50.00 \%)$ & $92(79.31 \%)$ & $982(71.42 \%)$ & $29(80.56 \%)$ & \\
\hline Dark or bright & $0(0 \%)$ & $0(0 \%)$ & $0(0 \%)$ & $0(0 \%)$ & $0(0 \%)$ & \\
\hline \multicolumn{7}{|l|}{ Style of hair coloring } \\
\hline No coloring & $505(24.75 \%)$ & $1(11.11 \%)$ & $35(23.18 \%)$ & $447(24.53 \%)$ & $22(37.93 \%)$ & \multirow{4}{*}{$\begin{array}{c}\chi^{2}(9)=46.28 \\
P<0.001 \\
{ }^{\mathrm{a}} \varphi=0.15 \\
\mathrm{n}=2040\end{array}$} \\
\hline Bleaching & $36(1.76 \%)$ & $2(22.22 \%)$ & $3(1.99 \%)$ & $28(1.54 \%)$ & $3(5.17 \%)$ & \\
\hline Simple coloring & $1180(57.84 \%)$ & $5(55.56 \%)$ & $\begin{array}{c}104 \\
(68.87 \%)\end{array}$ & $1046(57.41 \%)$ & $25(43.10 \%)$ & \\
\hline Salt and pepper & $319(15.64 \%)$ & $1(11.11 \%)$ & $9(5.96 \%)$ & $301(16.52 \%)$ & $8(13.79 \%)$ & \\
\hline
\end{tabular}

Abbreviations: NBW, normal birth weight; HBW, high birth weight; LBW, low birth weight; VLBW, very low birth weight.

$\varphi=$ effect size (phi coefficient or Cramer's V).

a A significant difference with an effect size $\geq$ Cohen's definition of "small".

${ }^{\text {b }}$ Not statistically significant.

between hair dyes and skin problems and cancers (15). Concerns were raised about the safety of cosmetics used during pregnancy; some women consider beauty products as a risk when they are expecting a child $(16,17)$. However, improvements and constant changes in the cosmetic industry and the limited evidence on the pregnancy-related effects of the hair dyes influence recommendations on using cosmetics during pregnancy. Even with the probability of toxic effects of cosmetics, to maintain beauty, women frequently dye their hair during pregnancy $(3,17)$. In our study, $75.24 \%$ of participants dyed their hair, and mostly, they did it in the third trimester. However, our results did not support our hypothesis on the association between late-pregnancy hair coloring and the Apgar scores. Despite finding a statistically significant association between preconception hair coloring and unfavorable Apgar scores, drawing a clinical inference is not biologically plausible.
Overall, NCs were more frequent among the women who did not color their hair, and the binary logistic regression model did not confirm a rise in overall NCs associated with hair coloring at any time during the pregnancy (OR: 0.027). Neither the product nor the amount of the dye used was associated with overall NCs. Our results showed that LBW was more frequent in women who dyed their hair in the preconception period or third trimester. Similar to our results, Jiang et al showed an association between prepregnancy hair dye and increased risk of LBW (4). Other studies investigated LBW in the hairdressers who had occupational exposure to the hair dye chemicals. However, the results were inconclusive (18). We may assume that women who dye their hair in the third trimester would belong to the group of women who use hair colors frequently to enhance self-image on the due date $(3,17)$. Hence, these women are more exposed to the chemicals in the hair dyes. This higher exposure might be associated 
with the LBW neonates, as Herdt-Losavio et al reported a slightly increased risk of LBW in cosmetologists (19). On the other hand, Chua-Gochecoet reported that the chemicals in the hair dyes would not reach the placenta substantially enough to cause harm unless there is a wound or an abscess in the scalp skin. They also concluded that they should not be concerned about the occasional use of hair colors during pregnancy (14).

Preterm labor occurred more frequently in cases of mothers who dyed their hair in the third trimester. Since we did not control the factors that would confound the association, we need more evidence considering the chemical substances in the hair dyes, detailed time of hair coloring, and other factors associated with preterm labor to reach to any conclusion.

The strength of the evidence is not sufficient to be recommended for the safety of the hair colors during pregnancy (SOR:C) (7). All the perinatal health professionals need to advise women about the benefits and risks of using cosmetics during pregnancy and provide valid information and informative considerations (16).

\section{Limitations}

The rate of specific complications was low, and it limited the statistical power of our study in the investigation of hair coloring and particular complications.

\section{Conclusions}

This study provided further evidence of an association between exposure to hair dyes and LBW. The odds for NCs was not increased. Dyeing hair is questionable for a healthy pregnancy, and pregnant patients are better to avoid all hair coloring products until definitive information is obtained.

\section{Availability of Data and Materials}

The datasets used and/or analyzed during the current study are available from the corresponding author on reasonable request.

\section{Authors' Contribution}

MSM and MK Shishavan were responsible for the main idea and design of the study. MSM supervised the study, contributed to writing the first draft, and approved the final version for submission. MSM was involved in planning the project, analyzing the statistics, and writing the first draft of the manuscript. MRR was involved in the design and implementation of the project. PMG, MG, VR, and ZT were assisted in implementing the project at all stages and critically revising the manuscript draft for the relevant content. All authors read and approved the final manuscript.

\section{Conflict of Interests}

Authors declare that they have no conflict of interests.

\section{Ethical Issues}

Ethical Approval was obtained from the National Research Ethics Committee, Tabriz University of Medical Sciences, on 8.27.2018 (Committee's reference number: IR.TBZMED.REC.1397.464). The project was found to be in accordance with the ethical principles and the national norms and standards for conducting medical research in Iran. Informed consent was obtained from all eligible patients before entering the study.

\section{Financial Support}

This study was funded by the Women's Reproductive Health Research Center, Tabriz University of Medical Sciences, Tabriz, Iran.

\section{Acknowledgments}

The authors would like to acknowledge Fariba Nikan and Asieh Ghasempoor (MSc students), who contributed to data collection. Further thanks of authors go to all patients who participated in this study, without their contribution, conducting the study was not possible.

\section{References}

1. Kunst A. Women's Hair Dye Usage in the U.S. 2017, By Age Group. Statistica website. https://www.statista.com/ statistics/719200/frequency-of-hair-dye-usage-in-the-us-byage-group/. Accessed April 15, 2020.

2. Patel D, Narayana S, Krishnaswamy B. Trends in use of hair dye: a cross-sectional study. Int J Trichology. 2013;5(3):140143. doi:10.4103/0974-7753.125610

3. Dehvari M, Ghaneian MT, Morowatisharifabad MA, Karimi $M$, Jasemizad T. Knowledge, Attitudes and Practice of Women About Adverse Effects of Cosmetics in Yazd City, Iran. Health Scope 2018;7:e68257. doi: 10.5812/jhealthscope.68257.

4. Jiang C, Hou Q, Huang Y, et al. The effect of pre-pregnancy hair dye exposure on infant birth weight: a nested casecontrol study. BMC Pregnancy Childbirth. 2018;18(1):144. doi:10.1186/s12884-018-1782-5

5. McCall EE, Olshan AF, Daniels JL. Maternal hair dye use and risk of neuroblastoma in offspring. Cancer Causes Control. 2005;16(6):743-748. doi:10.1007/s10552-005-1229-y

6. Couto AC, Ferreira JD, Rosa AC, Pombo-de-Oliveira MS, Koifman S. Pregnancy, maternal exposure to hair dyes and hair straightening cosmetics, and early age leukemia. Chem Biol Interact. 2013;205(1):46-52. doi:10.1016/j.cbi.2013.05.012

7. Zohra N, Frueh J. In pregnant women, does use of hair dye increase rates of adverse fetal outcomes? EvidenceBased Practice. 2017;20(6):10-11. doi:10.1097/01. ebp.0000541736.52208.31

8. Ball N. Glycol ethers and congenital malformations. Epidemiology. 2013;24(6):939-940. doi:10.1097/ EDE.0b013e3182a70807

9. Blackmore-Prince C, Harlow SD, Gargiullo P, Lee MA, Savitz DA. Chemical hair treatments and adverse pregnancy outcome among Black women in central North Carolina. Am J Epidemiol. 1999;149(8):712-716. doi:10.1093/ oxfordjournals.aje.a009879

10. Warembourg C, Botton J, Lelong N, et al. Prenatal exposure to glycol ethers and cryptorchidism and hypospadias: a nested case-control study. Occup Environ Med. 2018;75(1):59-65. doi:10.1136/oemed-2017-104391

11. Béranger R, Garlantézec R, Le Maner-Idrissi G, et al. Prenatal exposure to glycol ethers and neurocognitive abilities in 6-year-old children: the PELAGIE cohort study. Environ Health Perspect. 2017;125(4):684-690. doi:10.1289/ehp39

12. Nishihama $Y$, Tatsuta $N$, Iwai-Shimada $M$, et al. The association between gestational use of personal care products and neonatal urological abnormality at birth: The Japan Environment and Children's Study. Reprod Toxicol. 2020;93:83-88. doi:10.1016/j.reprotox.2020.01.005

13. Fox NS. Dos and don'ts in pregnancy: truths and myths. Obstet Gynecol. 2018;131(4):713-721. doi:10.1097/ aog.0000000000002517

14. Chua-Gocheco A, Bozzo P, Einarson A. Safety of hair products during pregnancy: personal use and occupational exposure. 
Can Fam Physician. 2008;54(10):1386-1388.

15. Kim KH, Kabir E, Jahan SA. The use of personal hair dye and its implications for human health. Environ Int. 2016;89-90:222227. doi:10.1016/j.envint.2016.01.018

16. Marie C, Cabut S, Vendittelli F, Sauvant-Rochat MP. Changes in cosmetics use during pregnancy and risk perception by women. Int J Environ Res Public Health. 2016;13(4):383. doi:10.3390/ijerph13040383

17. Gupta M. A study of knowledge, attitude and practices regarding hair dye use among general population. Our
Dermatology Online. 2018;9(1):15-18. doi:10.7241/ ourd.20181.4

18. Peters C, Harling M, Dulon M, Schablon A, Torres Costa J, Nienhaus A. Fertility disorders and pregnancy complications in hairdressers-a systematic review. J Occup Med Toxicol. 2010;5:24. doi:10.1186/1745-6673-5-24

19. Herdt-Losavio ML, Lin S, Druschel CM, Hwang SA, Mauer MP, Carlson GA. The risk of having a low birth weight or preterm infant among cosmetologists in New York State. Matern Child Health J. 2009;13(1):90-97. doi:10.1007/s10995-008-0324-6

(C) 2021 The Author(s); This is an open-access article distributed under the terms of the Creative Commons Attribution License (http:// creativecommons.org/licenses/by/4.0), which permits unrestricted use, distribution, and reproduction in any medium, provided the original work is properly cited. 